\title{
Apontamentos sobre a expansão do agronegócio da soja no decênio 2010 - 2019 no
}

\section{Município de Pontes e Lacerda-MT}

Notes regarding the expansion of soybean agribusiness in the decade 2010 - 2019 in Municipality

Pontes e Lacerda-MT

Notas sobre la expansión de la agroindustria de la soja en la década 2010 - 2019 en el Municipio de

Pontes e Lacerda-MT

Recebido: 18/10/2021 | Revisado: 25/10/2021 | Aceito: 28/10/2021 | Publicado: 31/10/2021

Paulo Daniel Curti de Almeida

ORCID: https://orcid.org/0000-0001-9211-3704 Instituto Federal de Educação, Ciência e Tecnologia de Mato Grosso, Brasil

E-mail: kurti.paulo@gmail.com

Gilson Pedro Ranzula

ORCID: https://orcid.org/0000-0002-9459-4668 Instituto Federal de Educação, Ciência e Tecnologia de Rondônia, Brasil E-mail: professorranzula@gmail.com

Luciana Alves Ranzula

ORCID: https://orcid.org/0000-0002-6546-520X Instituto Federal de Educação, Ciência e Tecnologia de Rondônia, Brasil E-mail: lucianalualbio@gmail.com

\begin{abstract}
Resumo
A dinâmica socioespacial da sociedade capitalista pode ser contemplada a partir da análise das ações engendradas pelas tradings atuantes no agronegócio, e especialmente aquelas integradas na cultura da soja, sendo elas um dos mais notáveis agentes da (re)organização e transformação do espaço do geográfico. Este artigo objetivou analisar algumas dinâmicas socioespaciais produzidas pelo agronegócio da soja no decênio 2010 - 2019, no município de Pontes e Lacerda, estado de Mato Grosso. Para a elaboração do artigo foi adotado como procedimento metodológico a revisão de literatura através de levantamento bibliográfico em livros, artigos científicos, anuários estatísticos (digitais e eletrônicos) e trabalho de conclusão de curso. Os dados secundários que subsidiaram as discussões foram acessados através da Produção Agrícola Municipal (PAM), no Sistema IBGE de Recuperação Automática (SIDRA), disponíveis no sítio da Fundação Instituto Brasileiro de Geografia e Estatística (IBGE). Constatou-se na análise dos dados utilizados que entre o primeiro e o último ano do decênio 2010 - 2019 no município de Pontes e Lacerda-MT, no que diz respeito a atividade da sojicultura, houve expansão de cerca de $250 \%$ da área plantada em hectares, aumento de $338 \%$ na quantidade produzida em toneladas e para o rendimento médio da produção (relação quilogramas por hectare) obtevese acréscimo de $24 \%$. Concluiu-se que o fenômeno observado na área englobada no estudo é fruto da intensificação da globalização econômica, da especialização dos lugares, das disputas regionais/nacionais/global e da crescente demanda pela commodity soja mercado internacional.
\end{abstract}

Palavras-chave: Antecipação espacial; Uso da terra; Commodity; Sojicultura.

\begin{abstract}
The socio-spatial dynamics of capitalist society can be seen from the analysis of the actions engendered by the tradings (very short-term investment modality, consisting in the purchase and sale of highly liquid shares) that are active in agribusiness, and mainly those integrated in the soy culture, that is one of the most notable agents of (re)organization and transformation of the geographic space. This article has the goal to analyze some socio-spatial dynamics that are produced by soy agribusiness in the decade 2010 - 2019, in Pontes e Lacerda municipality, State of Mato Grosso. For the elaboration of the article, the literature review was adopted as a methodological procedure through a bibliographic survey in books, scientific articles, statistical yearbooks (digital and electronic) and course conclusion work. Secondary data that supported the discussions were accessed through the Municipal Agricultural Production (PAM), in the IBGE Automatic Recovery System (SIDRA), that are available on the website of the Brazilian Institute of Geography and Statistics Foundation (IBGE). It was verified in the analysis of the data used that between the first and the last year of the decade 2010 - 2019 in Pontes e Lacerda-MT municipality, related to soy production, there was an expansion of about $250 \%$ of the planted area in hectares, an increase of $338 \%$ in the quantity produced in tons and for the average yield of production (kilogram ratio per hectare) an increase of $24 \%$ was obtained. It was verified that the phenomenon
\end{abstract}


observed in the area covered by the study is the result of the intensification of economic globalization, the specialization of places, regional/national/global disputes and the growing demand for commodity of soy in the international market. Keywords: Spatial anticipation; Land use; Commodity; Soy farming.

\section{Resumen}

La dinámica socioespacial de la sociedad capitalista se puede ver a partir del análisis de las acciones engendradas por la modalidad de inversión (modalidad de inversión de muy corto plazo, que consiste en la compra y venta de acciones de alta liquidez) que se encuentran activos en la agroindustria, y principalmente los integrados en el cultivo de la soja, que es uno de los agentes más destacados de (re) organización y transformación del espacio geográfico. Este artículo tuvo como objetivo analizar algunas dinámicas socioespaciales que fueron producidas por la agroindustria de la soja en la década 2010 - 2019, en el municipio de Pontes e Lacerda, estado de Mato Grosso. Para la elaboración del artículo fue adoptada la revisión de la literatura como procedimiento metodológico a través de un relevamiento bibliográfico en libros, artículos científicos, anuarios estadísticos (digitales y electrónicos) y trabajos de conclusión del curso. Los datos secundarios que apoyaron las discusiones fueron accedidos a través de la Producción Agropecuaria Municipal (PAM), en el Sistema de Recuperación Automática del IBGE (SIDRA), disponible en el sitio de la Fundación del Instituto Brasileño de Geografía y Estadística (IBGE). En el análisis de los datos utilizados fue verificado que entre el primer y el último año de la década 2010 - 2019 en la ciudad: Pontes e Lacerda-MT, con respecto a la producción de soja, hubo una expansión de alrededor del $250 \%$ del área sembrada en hectáreas, un aumento del $338 \%$ en la cantidad producida en toneladas y para el rendimiento promedio de producción (relación de kilogramos por hectárea) hubo un aumento del $24 \%$. Fue verificado que el fenómeno observado en el área cubierta en el estudio es el resultado de la intensificación de la globalización económica, la especialización de lugares, disputas regionales / nacionales / globales y la creciente demanda de la soja en el mercado internacional.

Palabras clave: Anticipación espacial; Uso de la tierra; Mercancía; Cultivo de soja.

\section{Introdução}

Para a compreensão da complexa dinâmica socioespacial da sociedade capitalista, faz-se necessária a análise das práticas espaciais empregadas pelas tradings do agronegócio (e especialmente aquelas integradas na cultura da soja), um dos mais notáveis agentes da organização e transformação do espaço. Assim, a ampliação das escalas geográficas dessas corporações coloca-as como um agente socioeconômico de constante e decisiva intervenção no processo de produção do espaço geográfico e, notoriamente, nos espaços mato-grossense e pontes-lacerdense, visto que eles têm sido palco de atuação de conglomerados empresariais do agronegócio da soja de forma mais intensa a partir da década de 1980 e a partir da década de 2000, respectivamente.

No Brasil, Hasse (2011) afirma que a soja chegou no final do século XIX e, ao longo da primeira metade do século XX, foi cultivada inicialmente por imigrantes europeus no estado do Rio Grande do Sul como planta forrageira e por japoneses no estado de São Paulo para a fabricação caseira de shoyo, tofu e missô.

Conforme a Empresa Brasileira de Pesquisa Agropecuária (Embrapa, 2021), no final da década de 1960, dois fatores internos fizeram o Brasil começar a enxergar a soja como um produto comercial, fato que mais tarde influenciaria no cenário mundial de produção do grão. Na época, o trigo era a principal cultura do Sul do Brasil e a soja surgia como uma opção de verão em sucessão ao trigo.

Diante desse cenário de elevação dos preços da commodity soja no mercado internacional paralelo a outros processos percebidos em escala nacional, é que o estado de Mato Grosso se inseriu no circuito embrionário do cultivo desta cultura. Segundo Moreno (2005), a soja começou a ser cultivada em Mato Grosso, comercialmente, no final da década de 1970, na região sudeste do estado e posteriormente foi se expandindo por outras áreas do bioma Cerrado, graças aos incentivos fiscais vinculados aos programas de desenvolvimento regional. Ela afirma também que a expansão da cultura visou, desde o início, atender a demanda do mercado externo pelo produto e seus derivados (principalmente farelo de soja). Segundo Siani e Hayashi (2021) a soja se consolidou como o principal produto agrícola brasileiro e ocupa 4\% do território do País.

Segundo a Organização das Nações Unidas para a Alimentação e a Agricultura (FAO, 2006, citada por Freitas, 2011), o Brasil dispõe de até 549 milhões de hectares para atividades agropecuárias, de cujo total, menos de 70 milhões de hectares 
estão sendo cultivados atualmente. É frisado também que do total da área agricultável do Brasil, cerca de 220 milhões de hectares estão cobertos com pastagens, dentre os quais 80 milhões de hectares em estado de degradação. Com a recuperação da área de pastagens degradadas, a pecuária bovina pode ser manter inalterada, liberando ainda 40 milhões de hectares para a produção de grãos e bioenergia.

Pela perspectiva das ações das tradings do agronegócio da soja, pode-se prever também que novas dinâmicas socioespaciais poderão ser produzidas, apoiando-se na observação de Corrêa (2007), que afirma que a antecipação espacial acaba sendo um critério das grandes corporações para assegurar o controle de uma dada organização espacial, sustentando, assim, as possibilidades, via a ampliação do espaço de atuação e de reprodução de suas condições de produção.

Com o despontar do século XX, as dinâmicas econômicas propagadas de forma multiescalar passaram a rodear o município de Pontes e Lacerda-MT (mapa 1). Dados da Produção Agrícola Municipal (PAM) disponibilizados pelo Instituto Brasileiro de Geografia e Estatística (IBGE, 2021) reforçam que até o ano de 2003, a sojicultura foi registrada de forma muito insípida no município, mas que a partir dali o fenômeno se desenhou de forma crescente no que concerne a área plantada e a outros atributos socioespaciais (quantitativos e qualitativos).

Mapa 1: Localização da área de estudo.

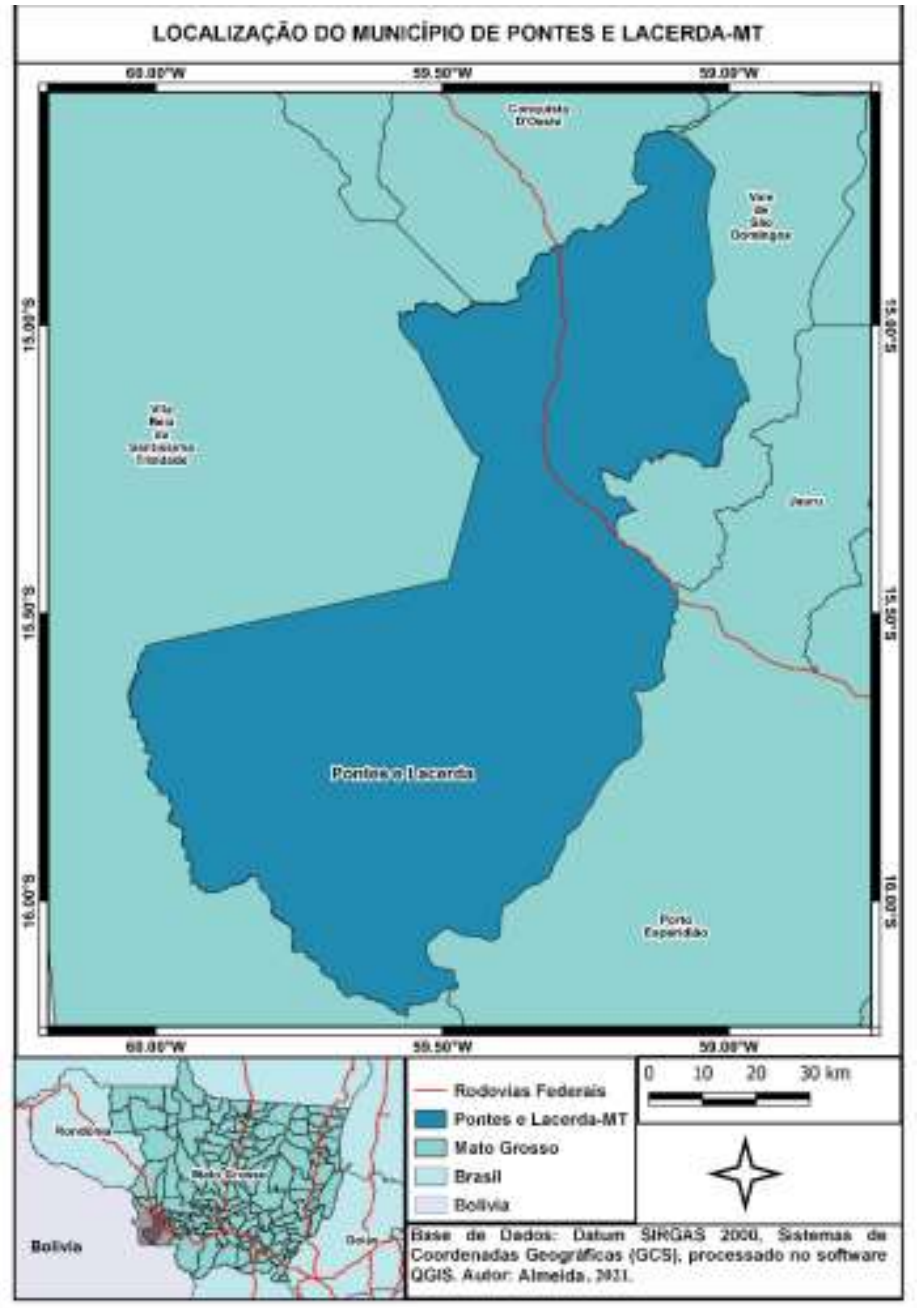

Fonte: dados vetoriais extraídos de https://www.ibge.gov.br/ e acessados em 11. set. 2021.

Diante desse cenário e tendo como sustentação a afirmação de Souza (2014, p. 14) quando é apontado que "cidades como Pontes e Lacerda, cuja base econômica está ligada ao extrativismo vegetal, pecuária e comércio, tem no plantio da soja a 
perspectiva de crescimento econômico com a introdução dessa oleaginosa" é que buscou-se entender a complexificação do processo de (re)produção do espaço geográfico pontes-lacerdense frente à expansão do agronegócio da soja.

A partir desses destaques introdutórios, aponta-se que este artigo tem por objetivo analisar as dinâmicas espaciais produzidas pelo agronegócio da soja no decênio 2010 - 2019, no município de Pontes e Lacerda, na microrregião Alto Guaporé, Sudoeste do estado de Mato Grosso.

\section{Metodologia}

Para o desenvolvimento de uma pesquisa científica é necessário seguir alguns pressupostos metodológicos na busca de dar legitimidade ao fenômeno estudado. E atentando-se ao objetivo que foi traçado, a pesquisa teve um caráter exploratório, uma vez que ela teve como suporte assuntos já discutidos em nossa sociedade e estudadas por diversos especialistas.

Assim, para a elaboração deste artigo foi adotado como procedimento metodológico a revisão de literatura através busca de dados secundários, onde realizou-se o de levantamento bibliográfico em livros, artigos científicos, anuários estatísticos (digitais e eletrônicos) e trabalho de conclusão de curso. Os dados expressos na tabela 1 que subsidiaram as discussões foram acessados através da Produção Agrícola Municipal (PAM), no Sistema IBGE de Recuperação Automática (SIDRA), disponíveis no sítio da Fundação Instituto Brasileiro de Geografia e Estatística (IBGE).

Na próxima seção os dados extraídos a partir da PAM foram colocados à luz da discussão permeada na introdução deste artigo e enriquecido com as contribuições do aporte de bibliográfico apresentado nas referências. Diante desses apontamentos, julgou-se que o percurso metodológico detalhado anteriormente foi eficaz para alcançar o objetivo proposto e trazer cientificidade à análise e discussão realizada.

\section{Resultados e Discussão}

A ciência geográfica tem como pressuposto principal observar a interação entre a sociedade e a natureza. A primeira como indutora de ações e intenções sobre a segunda, sendo essa o palco que enseja a nossa perpetuação como espécie. A partir da configuração do processo que Santos e Silveira (2001) denominam de aceleração contemporânea Santos (2006) infere que o campo tem-se apresentado com um espaço livre de rugosidades e por isso possuidor de uma flexibilidade muito superior à apresentada pelas cidades e, assim sendo, como local preferencial da expansão capitalista industrial/financeira e Sampaio e Rossini (2020) declaram que hoje o campo apresenta novas configurações espaciais, reveladas pela presença da agricultura capitalista.

No Brasil os setores econômicos vêm passando por intensa reestruturação produtiva nas últimas décadas, e a globalização da economia provocou transformações profundas também ao processo produtivo associado à agropecuária, pois segundo Arroyo (2005), as frações do território vinculadas ao mercado externo estão em permanente transformação por via da ação de empresas e instituições que operam, ou se projetam, na escala mundial com a pretensão de suprimir todo obstáculo à livre circulação de mercadorias, das informações e do dinheiro a partir de uma base material: portos, aeroportos, rodovias, ferrovias, hidrovias, armazenagens, impostos, regulamentos, acordos, leis etc., servindo a regulação dessas novas condições.

Já Bernardes (2005) assegura que o modelo de desenvolvimento que vem se afirmando em Mato Grosso desde os anos 1970, articulado pelo Estado, resultou na grande expansão do capital e prossegue avançando nos anos 2000 nos espaços ainda disponíveis, privilegiando o grande capital enquanto elemento indutor da ocupação daquela vasta fronteira de recursos. Ela cita Delgado (2012) que indica que a partir dos anos 2000, um novo modelo de acumulação emerge no setor agrícola brasileiro, no âmbito da política econômica e financeira do Estado, que se expressa na associação do capital agroindustrial com a grande 
propriedade fundiária e que "essa associação favorece a realização das estratégias econômicas do capital financeiro, no sentido de auferir maiores lucros sob o patrocínio das políticas de Estado" (Bernardes \& Lourenço, 2020, p. 289).

Bernardes (2005) aponta ainda que sustentados pelos processos de desterritorialização e reterritorialização em Mato Grosso, os agentes hegemônicos locais introduzem inovações que desestruturam forças produtivas anteriores, promovendo um processo de mudança estrutural na organização do espaço, em um cenário no qual as "novas" empresas desorganizam os territórios consolidados a fim de reorganizá-los para si, atendendo às suas novas necessidades e que

nesse sentido, a desigualdade espacial se vincula à divisão do trabalho, a qual é um meio para articular as relações sociais, sendo esse mecanismo social utilizado de forma distinta em sua adaptação a cada momento histórico e em sua articulação social do espaço. Assim sendo, uma característica marcante do capitalismo e seu desenvolvimento desigual no tempo e sua concretização desigual no espaço, constituindo esses aspectos elementos inseparáveis da dinâmica do desenvolvimento capitalista. (Bernardes, idem, p. 23)

Por conta das novas dinâmicas de interesse do grande capital nas áreas da "agricultura moderna", um dos fenômenos assistidos é a metamorfose da estrutura fundiária que caminha para a ampliação da histórica concentração fundiária em nosso País. Sobre essa conjuntura (Peixinho, 2005, p. 173) disserta que "a estrutura fundiária, nas áreas de cultivo de soja, tende a concentração, pois o modelo socioeconômico, baseado no patrimonialismo busca constantemente a concentração". Já Santos (2003, p. 175) explica que "devido às exigências da tecnologia, durante o atual período histórico, o aparato produtivo está se concentrando cada vez mais nas mãos de poucos e em um número limitado de pontos no espaço", Martins (2002, p. 201) reitera que "o latifúndio não está interessado em terra, mas em renda da terra" e Bini (2020) conclui que

em um patamar no qual a função da terra se manifesta hegemonicamente segundo os anseios do mercado verticalizado de commodities internacionais, sua posse especulativa sustenta a manutenção de uma lógica perversa que coloca o abastecimento de alimentos dependente de longos circuitos espaciais de circulação. (p. 38)

E em meio a ampliação das desigualdades socioespaciais sustentadas na produção do meio técnico-científicoinformacional, Santos e Silveira (2001, p. 25) afirmam que "toda forma de intermediação entre o homem e o meio ambiente constitui uma técnica" e Bernardes acrescenta que (2005) dado que o uso de técnicas modernas constitui a base da produção do espaço numa economia mundializada, os diferentes tipos de espaço nessa fronteira passam a diferenciar-se por sua diferente capacidade de oferecer rentabilidade às inversões em função de condições de ordem técnica e organizacional e que a fluidez e a velocidade das técnicas da informação articulam-se com as demais técnicas, produzindo lugares com novos conteúdos, ocorrendo o processo de (re)estruturação por meio da participação de ações políticas que contribuem para alterar a dinâmica local/regional. Nesse horizonte, Santos (2008, p. 193) complementa que "as técnicas atuais se difundiram universalmente, ainda que com diferente intensidade, e seus efeitos se fazem sentir, direta ou indiretamente, sobre a totalidade dos espaços".

Elias (2006) afirma que nas áreas onde se expande a agricultura científica, o meio natural e o meio técnico são rapidamente substituídos pelo meio técnico-científico-informacional, aumentando a proporção da natureza social sobre a primeira natureza. No Brasil, conforme a autora supracitada, esse quadro fez com que em pouco tempo, nosso país passasse de essencialmente agrário para uma das principais economias do mundo.

Elias (2021) também aponta que, apesar do uso ambíguo da palavra "agronegócio", ele passou a ser utilizado de forma corrente no Brasil há duas década, mas que apesar de sua pouca idade já carrega um caráter rodeado de significados, carregada de ideologias e mitos, estimulando a necessidade da apresentação de elementos de argumentação em direção a uma visão crítica em cima dele e que a própria formação da palavra deixa nítido que entre os maiores objetivos está a obtenção de lucro e renda 
da terra, através da produção de muitas novas mercadorias voltadas ao mercado urbano, nacional e internacional, de alimentos (ultra)processados, de commodities e de agrocombustíveis (agro + negócio).

O município de Pontes e Lacerda, localizado no sudoeste do estado de Mato Grosso foi criado por meio da Lei Estadual n. ${ }^{\circ} 4.167$, de 29 de dezembro de 1979, sendo que o seu território foi desmembrado do município de Vila Bela da Santíssima Trindade e conforme Ferreira (2001), a instalação oficial ocorreu em janeiro de 1981. Historicamente a área onde está inserido o município foi palco de atividades de extração vegetal e mineral, mas com a chegada de migrantes oriundos de outros estados da federação brasileira, a atividade da pecuária bovina avolumou-se, tornando o município destaque de efetivo de bovino no estado de Mato Grosso, ocupando em 2020 a sexta posição.

E no acirramento da "guerra dos lugares" configuradas de forma multiescalar a partir do início deste século o município passou a ser palco de outra dinâmica econômica: a chegada do agronegócio da sojicultura. Em Mato Grosso, consolidou-se ao longo das últimas décadas do século XX e ao longo deste século, a "região concentrada" da soja, no médio norte mato-grossense e tendo o município de Sorriso como grande destaque. Outros polos importantes também, como o de Campo Novo do Parecis, de Primavera do Leste, de Querência, da divisa de Mato Grosso com o Pará também se consolidaram ou estão em fase.

Mas por conta de novas oportunidades gestadas, como o aumento na demanda inter(nacional) pela soja e a possibilidade da Integração Lavoura-Pecuária (ILP), Pontes e Lacerda tem-se inserido no circuito sojífero e, conforme os dados apontados na Tabela 1, ampliando de forma quase constante, a área plantada e a quantidade produzida no decênio 2010 - 2019.

Tabela 1: Comportamento das variáveis analisadas ao longo do decênio 2010 - 2019.

\begin{tabular}{|c|c|c|c|c|c|}
\hline \multicolumn{2}{|c|}{ Área plantada (hectare) } & \multicolumn{2}{c|}{ Quantidade produzida (toneladas) } & \multicolumn{2}{c|}{ Rendimento da produção (quilogramas por hectare) } \\
\hline 2010 & 5.500 & 2010 & 16.500 & 2010 & 3.000 \\
\hline 2011 & 5.700 & 2011 & 15.960 & 2011 & 2.800 \\
\hline 2012 & 6.500 & 2012 & 19.500 & 2012 & 3.000 \\
\hline 2013 & 7.800 & 2013 & 23.400 & 2013 & 3.000 \\
\hline 2014 & 9.850 & 2014 & 23.400 & 2014 & 3.200 \\
\hline 2015 & 14.120 & 2015 & 46.596 & 2015 & 3.300 \\
\hline 2016 & 11.570 & 2016 & 40.958 & 2016 & 3.540 \\
\hline 2017 & 15.750 & 2017 & 55.755 & 2017 & 3.520 \\
\hline 2018 & 15.100 & 2018 & 53.152 & 2018 & 3.720 \\
\hline 2019 & 19.456 & 2019 & 72.376 & 2019 & \\
\hline
\end{tabular}

Fonte: <https://sidra.ibge.gov.br/Tabela/1612\#resultado>, acesso em 13. set. 2021. Organização: autores, (2021).

Acrescenta-se que a expansão da área cultivada, o crescimento da quantidade produzida de soja e o aumento do rendimento médio da produção por hectare, representa uma parte do cenário apresentado no parágrafo anterior, visto que, segundo Rodrigues (2009) em apenas cinco anos de plantio de soja foram recuperados pastos degradados por 40 anos de exploração de pecuária extrativista no município de Pontes e Lacerda-MT.

Por meio dos dados aportados na tabela 1, observou-se que houve aumento constante das três variáveis utilizadas no decênio 2010 - 2019, exceto nas seguintes situações: para a área plantada, houve recuo no ano de 2016 quanto ao no de 2015 e também do ano 2018 no que diz respeito ao ano de 2017; para a quantidade produzida ocorreu diminuição no ano de 2011 em referência ao ano de 2010, no ano de 2016 frente ao ano de 2015 e no ano de 2018 no que concerne ao ano de 2017; já para o rendimento médio da produção, observou -se que o encolhimento da produtividade no ano de 2011 em relação ao ano de 2010 e 
também no ano de 2018 no que tange ao ano de 2017. Esses recuos apontados podem ser relacionados a diversos fatores, tanto de ordem natural, quanto de ordem econômica. Para o recuo da área plantada em duas situações observadas, pode-se aventar que a relação econômica é um determinante direto, visto que cenários de menor lucratividade para o sojicultor diante do aumento dos custos dos diversos insumos utilizados e do encolhimento da demanda da soja no mercado externo tende a retrair a área plantada. Pelo olhar da natureza, sabe-se que a sojicultura é sensível às variações climáticas, pois tanto a escassez de chuvas no período da semeadura e do desenvolvimento da planta, quanto o excesso de chuvas no período da colheita podem incidir diretamente na produtividade e consequentemente na quantidade colhida.

De maneira geral, para as três variáveis apresentadas na tabela, destaca-se que entre o primeiro e o último ano do decênio abordado, ocorreram as seguintes alterações em termos percentuais: ocorreu a expansão de cerca de $250 \%$ da área plantada em hectares (Figura 1).

Figura 1: Variação da área de soja plantada (hectares) ao longo do decênio 2010 - 2019.

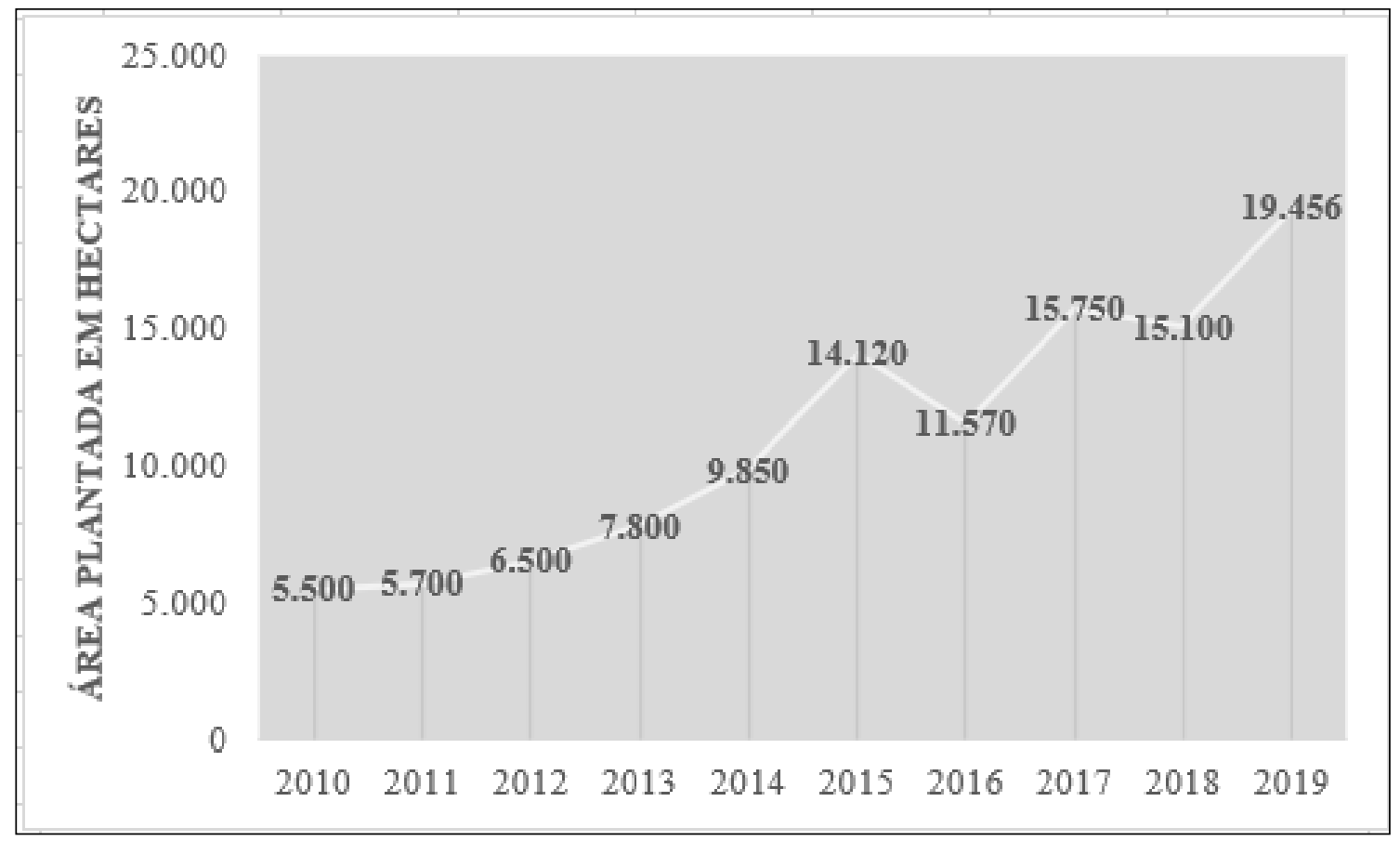

Fonte: <https://sidra.ibge.gov.br/Tabela/1612\#resultado>, acesso em 13. set. 2021. Organização: Autores, (2021).

Para a quantidade produzida em toneladas (Figura 2) a variação foi de cerca de $338 \%$ e para o rendimento médio da produção (relação quilogramas por hectare) obteve-se acréscimo de cerca de $24 \%$ (Figura 3). Da mesma maneira que se analisou os recuos da área plantada, da quantidade produzida e da produtividade em alguns anos, infere-se que as questões de ordens natural e econômica corroboraram diretamente para o crescimento entre os extremos das avariáveis analisadas. 
Research, Society and Development, v. 10, n. 14, e238101421938, 2021

(CC BY 4.0) | ISSN 2525-3409 | DOI: http://dx.doi.org/10.33448/rsd-v10i14.21938

Figura 2: Variação da quantidade de soja produzida (toneladas) ao longo do decênio 2010 - 2019.

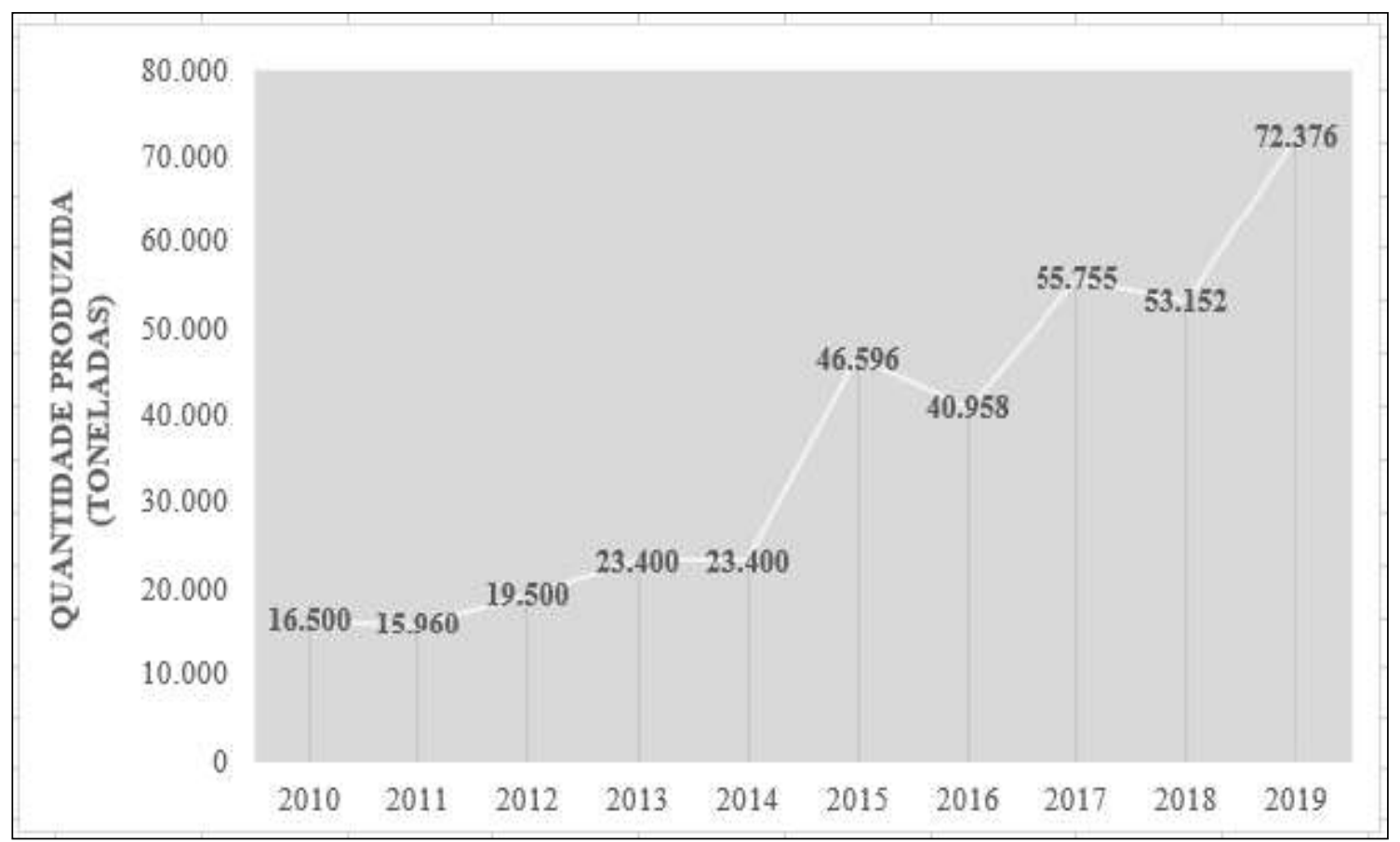

Fonte: $<$ https://sidra.ibge.gov.br/Tabela/1612\#resultado>, acesso em 13. set. 2021.

Organização: autores, (2021).

Figura 3: Variação do rendimento da produção (kg por hectare) ao longo do decênio 2010 - 2019.

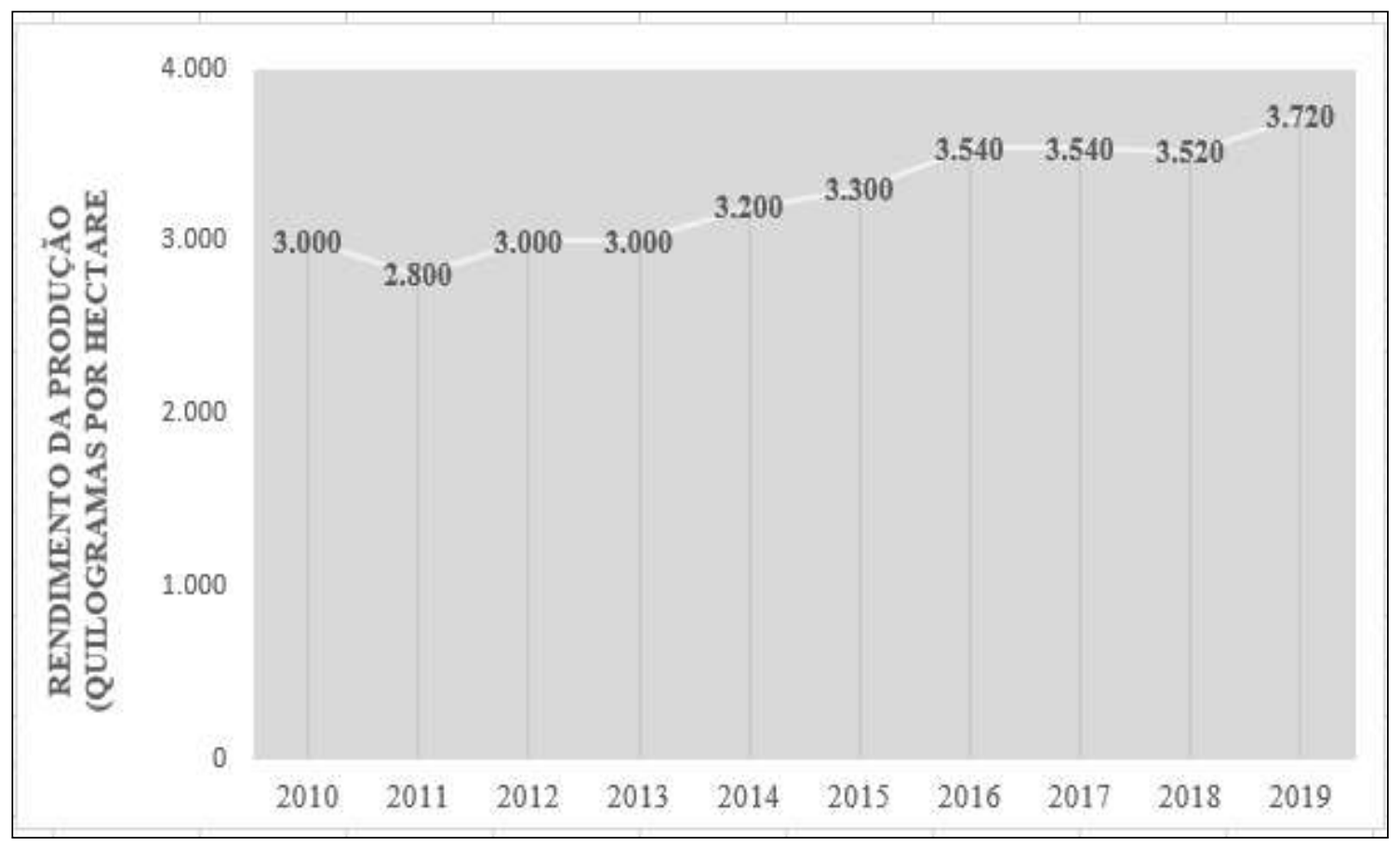

Fonte: <https://sidra.ibge.gov.br/Tabela/1612\#resultado>, acesso em 13. set. 2021.

Organização: autores, (2021).

Consequentemente, com a ampliação da área plantada e quantidade produzida, é possível afirmar que o valor da produção da soja no município também foi algo observado, visto que é uma relação direta e pode-se inferir também que, por ser uma commodity agrícola extremamente demandada no mercado (inter)nacional e diante da sua cotação em dólar, a valorização 
desta moeda sobre à brasileira provavelmente ampliou a elevação do valor da produção sojífera. $O$ valor total da produção saltou de R\$ 7.974.000,00 em 2010 para R \$ 72.376.000,00 em 2019 segundo a PAM consultada através do Sistema IBGE de Recuperação Automática (SIDRA) no sítio do IBGE. Sobre os possíveis impactos secundários frente à elevação da área plantada e quantidade produzida, pode-se aventar diversos resultados, visto que a cadeia de sustentação do agronegócio da soja é extremamente ampla e dinâmica. Elias (2020) afirma que

o agronegócio globalizado é um conjunto de atividades articuladas em rede, de forma totalmente interligada e multiescalar, e que contempla uma série de elementos: produção agropecuária; atividades industriais de transformação, beneficiamento e modificação desta agropecuária, comumente chamadas de agroindústria; indústrias de máquinas agrícolas, agrotóxicos, produtos veterinários; serviços de pesquisa agropecuária, finanças, extensão, logística, ensino tecnológico, marketing, assistência técnica, comércio exterior; comércios de fertilizantes, sementes melhoradas, peças para irrigação; redes de supermercados; fundos de investimentos; [...]. (p. 4)

No que diz respeito à análise do comportamento da variável "rendimento médio da produção (quilogramas por hectare)", vislumbra-se uma questão extremante favorável para a expansão da sojicultura no município de Pontes e Lacerda. Apontou-se que em 2019 foi registrado uma produtividade de 3.720 quilogramas por hectare no município, valor localizado acima da média da produtividade observado em Mato Grosso e no Brasil, que alcançaram respectivamente 3.185 e 3.316 quilogramas por hectare, conforme os dados da PAM do IBGE (2021). Daí que isso pode se tornar um grande atrativo para o aumento da importância do circuito sojífero na área de estudo e criar dinâmicas socioeconômicas, dada a extrema articulação de uma gama de atividades que possibilitam e configuram a sojicultura e foram apontadas anteriormente.

É importante apontar também que a própria evolução dos processos técnico-informacionais empregados na atividade levou a ampliação da produtividade. O melhoramento genético das sementes e o emprego de novas maquinarias que reconfigura a mecanização desta atividade em conjunto com novas práticas traz à luz o crescimento da produtividade que saltou de 1.732 quilogramas por hectare no Brasil e 2.006 em Mato Grosso no ano de 1990 para, respectivamente, 3.275 e 3.511 no ano de 2020. Para Santos (2008, p. 304) "com a globalização, a especialização agrícola baseada na ciência e na técnica inclui o campo modernizado em uma lógica competitiva que acelera a entrada da racionalidade em todos os aspectos da atividade produtiva". A teoria miltoniana compreende o atual estágio de produção do espaço geográfico vivenciado pela nossa sociedade, como aquele denominado de meio técnico-científico-informacional e que ele "é a cara geográfica da globalização" (idem, p. 239) onde os objetos mais proeminentes são elaborados a partir dos mandamentos da ciência e se servem de uma técnica informacional da qual lhes vem o alto coeficiente de intencionalidade com que servem às diversas etapas produtivas.

Assim, denota-se que a paisagem geográfica rural pontes-lacerdense produzida até o final de século XX a partir das dinâmicas relacionadas à exploração mineral e vegetal e ao desenvolvimento da pecuária extensiva (de corte, leiteira e de cria/recria) passou a incorporar o agronegócio da soja a partir do início dos anos 2000 e, diante dos dados apresentados na tabela 1 e dos argumentos produzidos nesta seção, vislumbra-se um cenário de continuidade de expansão da sojicultura na área pesquisada.

Em relação à paisagem geográfica urbana, torna-se necessária a averiguação aprofundada sobre a produção de novas dinâmicas socioespaciais na cidade de Pontes e Lacerda-MT. À luz dessa discussão, aponta-se Siani e Hayashi (2021) que mapearam e discutiram os impactos produzidos pela chegada da sojicultura na cidade de Rondon do Pará-PA e chegaram à conclusão que ela se metamorfoseou depois que a cultura da soja foi implantada, pois, houve alteração na cultura local e que a cidade passou a ser moldada a partir das necessidades do agronegócio e na perspectiva dos autores citados, esse quadro deixa/rá Rondon do Pará-PA mais vulnerável, visto que todo o agronegócio dela está baseado na produção da soja e ela, como commodity, possui variáveis alijadas do domínio dos sojicultores. 


\section{Considerações Finais}

A partir da afirmação que a ciência geográfica tem como pressuposto principal observar a relação entre a sociedade e o meio onde ela está inserida, considera-se uma questão central a metamorfose espacial produzida pela expansão do agronegócio da soja no município de Pontes e Lacerda-MT, visto que, sustentou-se através de diversas inferências que a ampliação do consumo e uso sojíferos nacional e globalmente tende a oportunizar novos recortes espaciais a se tornarem aptos ao atendimento dessa demanda crescente.

Aponta-se que a apropriação e a (re)produção do espaço geográfico configurou-se através de diversos movimentos humanos em direção a área de estudo deflagrados a partir do final do século XIX por conta da atividade de exploração da poaia. Pode-se aventar que essa ação não teve força para incrementar de forma substancial novas dinâmicas socioespaciais naquilo que hoje está estabelecido o município de Pontes e Lacerda.

Os deslocamentos humanos mais incisivos que conseguiram gestar alterações na paisagem pontes-lacerdense começaram a ser produzidos a partir de meados do século passado com a chegada de migrantes de diversos estados da federação brasileira, com destaque principalmente para os paulistas e goianos. Esse processo configurou a antecipação espacial por parte daqueles atores que seguiu-se tendo como sustentação o desenvolvimento de atividades primárias: extrativismo (vegetal e mineral) pecuária extensiva. As novas dinâmicas espaciais conseguintes pautaram-se na incorporação de novas perspectivas de inserção do capital inter(nacional) na área de estudo, por meio do ingresso de tradings do agronegócio e, que, na perspectiva da ciência geográfica, vislumbra-se como uma ação dicotômica, pois esses atores expressivos trazem consigo enigmáticas (re)apropriações e re(usos) do território outrora concebido.

Sendo assim, pode-se afirmar que o rearranjo das atividades econômicas em Pontes e Lacerda-MT ao longo, principalmente das últimas duas décadas, é fruto da intensificação da globalização econômica, da especialização dos lugares, das disputas regionais/nacionais/global e da crescente demanda por commodities agrícolas no mercado internacional (notoriamente a soja). Outrossim, olhando para o território brasileiro e mato-grossense, outros recortes espaciais vislumbraram, de forma semelhante, a (re)organização das suas atividades produtivas também para atender aos novos impulsos da sociedade capitalista atual.

Ressalta-se que o fenômeno da expansão da sojicultura sobre o município de Pontes e Lacerda-MT, além das implicações quantitativas apresentadas na seção anterior, apresenta tendência de continuidade a partir do cenário nacional/global atual. A participação dos atores estabelecidos e de outros que podem passar a atuar predispõe a configuração de um quadro complexo, visto que novas dinâmicas no que diz respeito ao emprego, ao valor de aluguéis, a alteração da estrutura fundiária e do uso da terra e do custo de vida da população pontes-lacerdense, dentre outras, estão sendo configuradas.

Por fim, reforça-se a importância da realização de pesquisas científicas mais acentuadas visando retratar qualitativa e quantitativamente os aspectos citados no parágrafo anterior e também estudos comparativos entre o processo descrito e aquilo que se percebe(u) em outros recortes espaciais mato-grossense onde a sojicultura está consolidada. Tais ações poderão subsidiar a proposição de políticas públicas com o intuito de atender de forma equilibrada as demandas das/dos pontes-lacerdenses.

\section{Referências}

Arroyo, M. M. (2005). Dinâmica territorial, circulação e cidades médias. In L. C. Dias, \& R. L. L. Silveira (Orgs.), Redes, sociedades e territórios (pp. 71-85). EDUNISC.

Bernardes, J. A. (2005). Circuitos espaciais da produção na fronteira agrícola moderna: BR-163 mato-grossense. In J. A. Bernardes, \& O. L. Freire Filho (Orgs.), Geografias da Soja - BR 163: fronteiras em mutação (pp. 13-37). Arquimedes Edições. 
Research, Society and Development, v. 10, n. 14, e238101421938, 2021

(CC BY 4.0) | ISSN 2525-3409 | DOI: http://dx.doi.org/10.33448/rsd-v10i14.21938

Bernardes, J. A, \& Lourenço, T. C. M. (2020). Estratégias territoriais da agricultura empresarial na fronteira agrícola moderna da BR-158 Mato-Grossense. In R. E. Rossini, M. R. I. M. Machado, \& M. A. P. Sampaio (Orgs.), Terra e trabalho: territorialidades e desigualdades, Vol.2 (pp. 279-306). FFLCH/USP. https://doi.org/10.11606/9786587621333.

Bini, D. L. C. (2020). O espaço dividido no Brasil agrícola. In R. E. Rossini, M. R. I. M. Machado, \& M. A. P. Sampaio (Orgs.), Terra e trabalho: usos e abusos do espaço agrário brasileiro, Vol.1 (pp. 17-43). FFLCH/USP. https://doi.org/10.11606/9786587621388.

Corrêa, R. L. (2007). Espaço: um conceito-chave para a Geografia. In I. E. Castro, P. C. C. Gomes, \& R. L. Corrêa (Orgs.), Geografia: conceitos e temas (pp. 279-306). Bertrand Brasil.

Elias, D. (2006). Novas dinâmicas territoriais no Brasil agrícola. In E. S. Sposito, M. E. B. Sposito, \& O. Sobarzo (Orgs.), Cidades médias: produção do espaço urbano e regional (pp. 279-306). Expressão Popular.

Elias, D.. (2020). A região metropolitana como recorte espacial para estudos sobre o agronegócio: questões de método e metodologia. Boletim Goiano de Geografia, 1(40), 1-28. https://doi: 10.5216/BGG.v40.63448.

Elias, D.. (2021). Mitos e nós do agronegócio no Brasil. Geousp, 25(2), 1-18. https://doi.org/10.11606/issn.2179-0892.

Empresa Brasileira de Pesquisa Agropecuária. (2021, Agosto, 28). História da soja. https://www.embrapa.br/soja/cultivos/soja1/historia.

Ferreira, J. C. V. (2001). Mato Grosso e seus municípios. Buriti.

Freitas, M. C. M. (2011). A cultura da soja no Brasil: O crescimento da produção brasileira e o surgimento de uma nova fronteira agrícola. Enciclopédia Biosfera. 7(12). Recuperado de https://conhecer.org.br/ojs/index.php/biosfera/article/view/4287.

Hasse, G. (2011). A rainha do agronegócio: a história da soja no Brasil. Coruja.

Instituto Brasileiro de Geografia e Estatística. (2021, Agosto, 26). Sistema IBGE de Recuperação Automática - Banco de Tabelas Estatísticas (SIDRA). https://sidra.ibge.gov.br/home/ipp/brasil.

Martins, J. S. (2002). A sociedade vista do abismo: novos estudos sobre exclusão, pobrezas e classes sociais. Vozes.

Moreno, G. (2005). Agricultura: Transformações e tendências. In G. Moreno, \& T. C. S. Higa (Orgs.), Geografia de Mato Grosso: território, sociedade, ambiente (pp. 140 - 171). Entrelinhas.

Peixinho, D. M. (2005). A espacialização da soja em Mato Grosso. In J. A. Bernardes, \& O. L. Freire Filho (Orgs.), Geografias da Soja - BR 163: fronteiras em mutação (pp. 154-75). Arquimedes Edições.

Rodrigues, A. (2009). Tendências promissoras: integração entre lavoura e confinamento contribui para redução de custos e diversificação dos negócios. $A G-A$ Revista do Criador. https://edcentaurus.com.br/ag/edicao/128/materia/2209.

Sampaio, M. A. P. \& Rossini, R. E. (2020). Cartografia exploratória, cartografia de síntese e estudos populacionais: uma reflexão sobre a evolução histórica da (re)produção do espaço agrário no Brasil. In R. E. Rossini, M. R. I. M. Machado, \& M. A. P. Sampaio (Orgs.), Terra e trabalho: usos e abusos do espaço agrário brasileiro, Vol.1 (pp. 45-93). FFLCH/USP. https://doi.org/10.11606/9786587621388.

Santos, M. (2003). Economia espacial: críticas e alternativas. (2. ${ }^{\mathrm{a}}$ ed.). EDUSP.

Santos, M. (2006). Por uma outra globalização: do pensamento único à consciência universal. (13. a ed.). Record.

Santos, M. (2008). A natureza do espaço: técnica e tempo, razão e emoção. (4. ${ }^{\mathrm{a}}$ ed.). EDUSP

Santos, M. \& Silveira, M. L. (2001). O Brasil: território e sociedade no século XXI. Record.

Siani, S. R. \& Hayashi, C. Transformações urbanas no sudeste do Pará e os impactos recentes trazidos pelas fazendas de soja. Research, Society and Development, 10(10), p. e47101018416. http://dx.doi.org/10.33448/rsd-v10i10.18416.

Silva, F. V. (2016). A logística e os circuitos espaciais da produção do agronegócio: uma análise do cenário mato-grossense. In J. A. Bernardes, É. A. Buhler, \& M. V. V. Costa (Orgs.). As novas fronteiras do agronegócio: transformações territoriais em Mato Grosso. (pp. 122-141). Lamparina.

Souza, V. R. (2014). A evolução da soja no município de Pontes e Lacerda-MT. [Trabalho de conclusão de curso não publicado]. Instituto Federal de Educação, Ciência e Tecnologia de Mato Grosso, campus Pontes e Lacerda. 